\title{
(6) OPEN ACCESS \\ A systematic review of the association between pleural plaques and changes in lung function
}

\author{
Leonid Kopylev, Krista Yorita Christensen, James S Brown, Glinda S Cooper
}

\begin{abstract}
- Additional material is published online only. To view please visit the journal online (http://dx.doi.org/10.1136/ oemed-2014-102468)

National Center for Environmental Assessment Office of Research and Development, United States Environmental Protection Agency, Washington DC, USA
\end{abstract}

Correspondence to Dr Leonid Kopylev, Mailstop 8623P, 1200 Pennsylvania Ave NW, Washington, DC 20460, USA; Kopylev.Leonid@epa.gov

Received 20 July 2014 Revised 13 October 2014 Accepted 18 November 2014 Published Online First 12 December 2014

\section{CrossMark}

\author{
To cite: Kopylev L, \\ Christensen KY, Brown JS, \\ et al. Occup Environ Med \\ 2015:72:606-614.
}

\begin{abstract}
Objectives To conduct a systematic review of changes in lung function in relation to presence of pleural plaques in asbestos-exposed populations.

Methods Database searches of PubMed and Web of Science were supplemented by review of papers' reference lists and journals' tables of contents. Methodological features (eg, consideration of potential confounding by smoking) of identified articles were reviewed by $\geq$ two reviewers. Meta-analyses of 20 studies estimated a summary effect of the decrements in per cent predicted (\%pred) forced vital capacity (FVC) and forced expiratory volume in $1 \mathrm{~s}\left(\mathrm{FEV}_{1}\right)$ associated with presence of pleural plaques.

Results Among asbestos-exposed workers, the presence of pleural plaques was associated with statistically significant decrements in FVC (4.09\% pred, 95\% Cl 2.31 to 5.86$)$ and $\mathrm{FEV}_{1}$ (1.99\%pred, 95\% Cl 0.22 to 3.77$)$. Effects of similar magnitude were seen when stratifying by imaging type (X-ray or highresolution (T) and when excluding studies with potential methodological limitations. Undetected asbestosis was considered as an unlikely explanation of the observed decrements. Several studies provided evidence of an association between size of pleural plaques and degree of pulmonary decrease, and presence of pleural plaques and increased rate or degree of pulmonary impairment.

Conclusions The presence of pleural plaques is associated with a small, but statistically significant mean difference in FVC and $\mathrm{FEV}_{1}$ in comparison to asbestosexposed individuals without plaques or other abnormalities. From a public health perspective, small group mean decrements in lung function coupled with an increased rate of decline in lung function of the exposed population may be consequential.
\end{abstract}

\section{INTRODUCTION}

Asbestos is the generic name for a group of naturally occurring silicate minerals that crystallise in long thin fibres. Asbestos has been used in a wide range of applications such as insulation, friction materials and textiles; worldwide asbestos usage peaked around the 1970s and has since declined due to regulations enacted to decrease or prevent exposure. ${ }^{1}$ However, such regulations vary by region and country, and considerable amounts of asbestos are still used today-for example, the US Geological Survey estimated that the worldwide production of asbestos was nearly 2 million metric tons in 2012 , and that the USA consumed 1020 metric tons of asbestos for applications (almost exclusively in the chloralkali industry and roofing products). ${ }^{2}$ Further, naturally occurring asbestos is wide spread in the USA. $^{3}$ Asbestos exposure and subsequent health effects continue to be a public health concern.
Asbestos has long been known to cause mesothelioma, along with lung and various other cancers (eg, laryngeal and ovarian). ${ }^{1}$ Asbestos is also known to cause various non-cancer effects in the lung (eg, asbestosis) and/or the pleura (eg, pleural plaques, diffuse pleural thickening (DPT)). Pleural plaques are one of the earliest and most common manifestations of asbestos-related disease. Pleural plaques are lesions in the tissue surrounding the lungs and lining the chest cavity. ${ }^{4}$

Pleural plaque prevalence increases with increasing time since first exposure; in some cohorts, after decades of follow-up, the prevalence of pleural plaque is over $80 \% .^{5}{ }^{6}$ The impact of pleural plaques has been debated in the literature. The American Thoracic Society (ATS), ${ }^{4}$ stated that "Although pleural plaques have long been considered inconsequential markers of asbestos exposure, studies of large cohorts have shown a significant reduction in pulmonary function attributable to the plaques, averaging about $5 \%$ of FVC, even when interstitial fibrosis (asbestosis) is absent radiographically...Decrements, when they occur, are probably related to early subclinical fibrosis." The American College of Chest Physicians (ACCP) ${ }^{7}$ published a Delphi study conducted to gauge consensus among published asbestos researchers, and found that these researchers rejected the statement that "Pleural plaques alter pulmonary function to a clinically significant degree." However, neither the ATS nor the ACCP statements were based on a formal systematic review of the literature. Recently, Wilken et $a l^{8}$ performed a systematic review and meta-analysis, examining pulmonary function in relation to the combined category of pleural plaques and/or DPT. DPT is thought to be a more severe health outcome compared with pleural plaques, and associated with more severe decrements in lung function. ${ }^{4}$ Mixing the two end points does not allow evaluation of the effect of pleural plaques alone.

Our objective was to conduct a systematic evaluation of cross-sectional and longitudinal studies examining the relationship between pleural plaques and lung function, focusing on changes in per cent predicted (\%pred) forced vital capacity (FVC) and forced expiratory volume in $1 \mathrm{~s}\left(\mathrm{FEV}_{1}\right)$, the most commonly reported measures in the identified studies. We considered X-ray studies and newer high-resolution CT (HRCT) studies.

\section{METHODS}

\section{Literature search strategy}

The search was conducted on 25 September 2013 using the PubMed and Web of Science databases with no publication date limitations; the search 
strategy (including search strings) is summarised in online supplementary figure 1 , with additional details of the process described below.

Standardised guidelines for defining plaques using radiographic evaluation are provided by the International Labour Organization (ILO), and have changed over time. The 1980 ILO guidelines ${ }^{9}$ defined circumscribed pleural thickening (ie, pleural plaques). The 2000 ILO revision ${ }^{10}$ defined a new category of localised pleural thickening (LPT) comprising only those plaques with width of at least $3 \mathrm{~mm}$ (intended to reduce the number of false-positive findings), and including plaques found on sites other than the chest wall (eg, diaphragm). Both pleural plaques as defined by the earlier ILO guidelines, and LPT as defined by the 2000 guidelines, were included in our literature search. There are no standardised guidelines similar to the ILO for defining pleural plaques using HRCT; thus, we used the authors' descriptions of the definition for pleural plaques.

The searches yielded 184 hits in PubMed, and 183 hits in Web of Science; after excluding duplicate citations, 262 remained for further review. On the basis of a title and abstract screen, 105 citations were excluded because they were not directly relevant to the study question (eg, no pulmonary function measurements). The remaining 157 citations were selected for full-text review by a group of three reviewers to determine if they contained data addressing our study question. Each paper was reviewed independently by two of the three reviewers. In cases of disagreements or uncertainty (eg, questions about the definition of pleural abnormality used), the third reviewer also reviewed the paper and participated in the consensus building discussions. Studies were also excluded at this step if the analysis group included individuals with DPT or was based on undefined pleural abnormalities $(n=21)$, or if they included individuals with parenchymal abnormalities (defined as X-ray profusion score $>1 / 0$, or HRCT evidence of parenchymal abnormality) without presenting a stratified analysis showing the results for the effect of pleural plaques in the absence of parenchymal abnormality $(n=7)$. Thirty studies were selected for inclusion through this process, and eight additional references were identified through (1) a review of references in reviews and in the identified primary source studies and (2) by searching the Table of Contents of relevant journals for newly released papers (September-December 2013) of selected journals (see online supplementary material) for a total of 38 primary source studies. All of the X-ray studies used in these meta-analyses stated that they used the outcome of pleural plaques as defined by the 1980 ILO guidelines; no studies reported LPT as defined by the 2000 ILO guidelines. If more than one publication presented data on the same study participants or on a subset of the study participants, or provided additional methodological details about a study, these publications are treated as related (with one entry in the summary tables and analysis). Some studies presented both longitudinal and crosssectional data from the same study population; the longitudinal and cross-sectional results were considered separately.

In the next step of this review process, each of the selected studies was evaluated for attributes related to study methods. Again, two of the three reviewers independently abstracted information pertaining to: selection of participants, protocols for X-ray or HRCT readings, protocols for spirometry measurements, analytic approach and consideration of smoking as a potential confounder (see online supplementary table S1). These criteria were defined a priori. This information was not used as a basis for exclusion, but rather to identify studies with limitation(s) of sufficient magnitude to potentially affect the interpretation of the study results.
For the purpose of developing a summary effect estimate across studies, cross-sectional studies were considered separately from longitudinal studies. Among the cross-sectional studies, 25 used an internal comparison group (ie, comparison of pleural plaque vs no pleural plaque groups among individuals with asbestos exposure), and 10 included only an external comparison group (ie, the comparison was between asbestos exposed individuals with pleural plaques and people without asbestos exposure). The 10 studies with only an external comparison group $^{11-20}$ were excluded since an internal comparison better estimates the effect of pleural plaques themselves by reducing potential confounding (ie, greater similarity between groups with regard to exposure, smoking, socioeconomic status, work status and general health).

\section{Meta-analysis}

Each of the 20 cross-sectional, internal comparison studies that provided usable data on (1) the number of individuals with and without pleural plaques and (2) mean values for the \%pred respiratory measures of interest in each group, were included in further analysis. Four studies reported vital capacity (VC) rather than $\mathrm{FVC}^{21-24}$ and were included in the analysis together with the rest of the studies. In total, 15 X-ray studies ${ }^{21} 2325-37$ and 5 HRCT $^{22} 2438-40$ studies were used for the analysis of mean difference in FVC; $10 \mathrm{X}$-ray studies and 5 HRCT studies were used for the analysis of mean difference in $\mathrm{FEV}_{1}$. The results from each study were presented in graphical form, grouping results of similar type (eg, difference in \%pred, FVC). Summaries of the 20 included studies are shown in table 1 (X-ray studies) table 2 (HRCT studies). Five cross-sectional studies were excluded because results were presented as absolute values rather than \%pred, ${ }^{41}$ sample sizes in relevant groups were not reported, ${ }^{42}$ or quantitative results were not reported. ${ }^{43-45}$ Online supplementary table S2 contains summaries of the 5 excluded studies. Additional details regarding study evaluation and analytical issues (eg, calculation of SD when not provided in published results), along with more detailed tables of abstracted methodological information, are included in the online supplementary material.

Data entry was performed independently by two people and any inconsistencies were resolved by discussion and verification with the original study. All statistical analyses were performed in $\mathrm{R}$ software; the R package Metafor ${ }^{46}$ was used for conducting the meta-analyses. A random effects model was used for FVC and $\mathrm{FEV}_{1}$. Summary estimates and the $95 \%$ CIs are reported for each outcome. To assess possible publication bias, funnel plots were evaluated.

Both X-ray and HRCT studies were included in the analysis. Analyses stratified into these two groups were also conducted, to investigate potential differences based on detection method. HRCT has been reported to have greater sensitivity and specificity compared with chest X-ray for the detection of pleural abnormalities; ${ }^{47}$ only $50-80 \%$ of cases of pleural thickening documented by HRCT are identified on X-ray. ${ }^{4}$ HRCT is better able to differentiate such thickening from subpleural fat pads, and to identify parenchymal abnormalities.

All inferences are based on a comparison between exposed individuals with no radiographic or HRCT abnormalities and exposed individuals with pleural plaques only (ie, without any other radiographic or HRCT abnormalities). The studies using HRCT, published between 1999 and 2011, used a variety of descriptions to describe the pleural plaque group (see table 2; standardised guidelines for classification of pleural abnormalities identified using HRCT are not currently available). 
Table 1 Cross-sectional (internal comparison group) X-ray studies of pleural plaques and lung function included in meta-analysis

\begin{tabular}{|c|c|c|c|}
\hline Reference, population & $\mathrm{X}$-ray details & Smoking consideration & Study groups \\
\hline $\begin{array}{l}\text { Bresnitz et a }{ }^{25} \text { Philadelphia } \\
\text { Construction-elevator } \\
\text { Screening programme through union, 1988. } n=91 \text { ( } \\
\text { eligible not available) }\end{array}$ & Two readers, blinded & $\begin{array}{l}\text { Authors noted no association between } \\
\text { pleural abnormalities and smoking }\end{array}$ & $\begin{array}{l}\text { Excluded profusion scores } \geq 1 / 0 \\
\text { Pleural thickening, } n=20 \text { ( } 15 \text { bilateral, } \\
5 \text { unilateral) } \\
\text { No pleural abnormalities, } n=71\end{array}$ \\
\hline $\begin{array}{l}\text { Di Lorenzo et } a^{26} \text { Italy } \\
\text { Asbestos cement factory } \\
\text { Recruited through union } \\
\mathrm{n}=30 \text { (of } 35,86 \% \text { participation) } \\
\text { Eligibility criteria not described }\end{array}$ & Two readers, blinded & $\begin{array}{l}\text { Authors noted smoking distribution } \\
\text { similar across groups }\end{array}$ & $\begin{array}{l}\text { Excluded profusion scores } \geq 1 / 1 \\
\text { Pleural plaques, } n=10 \text {, } \\
\text { No bronchial, parenchymal or pleural } \\
\text { disease, } n=9\end{array}$ \\
\hline $\begin{array}{l}\text { Dujić et a }{ }^{27} \text { Croatia } \\
\text { Asbestos cement factory } \\
\text { Current and retired workers } \\
\mathrm{n}=344,284 \text { current and } 58 \text { retired workers }(92 \% \text { and } \\
52 \% \text { participation, respectively) }\end{array}$ & Two readers, blinded & $\begin{array}{l}\text { Difference in smoking prevalence }(62 \% \\
\text { vs } 38 \%) \text { not addressed }\end{array}$ & $\begin{array}{l}\text { Excluded profusion scores } \geq 1 / 1 \\
\text { Isolated pleural plaques, } n=55 \\
\text { Workers with no radiographic change, } \\
n=255\end{array}$ \\
\hline $\begin{array}{l}\text { García-Closas and Christiani }{ }^{28} \text { Massachusetts } \\
\text { Construction-carpenters } \\
\text { Invited by union } 1987-1988 \\
\mathrm{n}=631,618 \text { current and } 13 \text { retired workers ( } 16 \% \text { and } \\
3 \% \text { participation, respectively) }\end{array}$ & Two readers, blinded & $\begin{array}{l}\text { Less than } 10 \% \text { difference in smoking } \\
\text { prevalence between groups }\end{array}$ & $\begin{array}{l}\text { Excluded profusion scores } \geq 0 / 1 \\
\text { Circumscribed plaque without obliteration of } \\
\text { costophrenic angle, } n=64 \\
\text { No X-ray abnormalities, } n=457\end{array}$ \\
\hline $\begin{array}{l}\text { Hilt et a }{ }^{29} \text { Norway } \\
\text { Asbestos-exposed workers } \\
\text { County-wide screening, } n=21483 ; 1431 \text { referred for } \\
\text { re-examination if X-ray abnormalities } \\
n=1372(96 \%) \text { participated }\end{array}$ & $\begin{array}{l}\text { Two readers, blinding not } \\
\text { reported }\end{array}$ & $\begin{array}{l}\text { Percentage predicted included smoking } \\
\text { variable }\end{array}$ & $\begin{array}{l}\text { Profusion scores details not discussed } \\
\text { Pleural plaques only, } n=363 \\
\text { No abnormalities, previous exposure } \\
\text { reported, } n=98\end{array}$ \\
\hline $\begin{array}{l}\text { Järvholm and Sandén }{ }^{30} \text { Sweden } \\
\text { Shipping industry } \\
\text { General screening 1977-1979 } \\
n=3904 \text { participated; participation rate not reported }\end{array}$ & $\begin{array}{l}\text { One reader from group of } \\
\text { three, blinding not } \\
\text { reported }\end{array}$ & Limited to nonsmokers & $\begin{array}{l}\text { Circumscribed thickening, } n=87 \\
\text { No } X \text {-ray abnormalities, } n=115\end{array}$ \\
\hline $\begin{array}{l}\text { Järvholm and Larsson }{ }^{23} \text { Sweden } \\
\text { Asbestos-exposed workers } \\
\text { General screening } 1976 \\
n=4268 \text {, participation rate not reported }\end{array}$ & $\begin{array}{l}\text { One reader from group, } \\
\text { blinding not reported }\end{array}$ & Analyses stratified by smoking status & $\begin{array}{l}\text { Profusion scores details not discussed } \\
\text { Calcifications typically localised on the } \\
\text { diaphragm or chest wall, } n=130 \\
\text { No pleural plaques, } n=1103\end{array}$ \\
\hline $\begin{array}{l}\text { Miller et } a^{\beta 1} \text { USA, Canada } \\
\text { Insulation workers } \\
1981-1983 \text { screening of cohort established in } 1967 \\
n=2611 \text {, participation rate approximately } 40 \%\end{array}$ & One reader, blinded & $\begin{array}{l}\text { Smoking data by group not reported } \\
\text { and not included in analysis. }\end{array}$ & $\begin{array}{l}\text { Included profusion scores } 0 /- \text { or } 0 / 0 \\
\text { Circumscribed pleural plaques, } n=121 \\
\text { No pleural thickening, } n=203\end{array}$ \\
\hline $\begin{array}{l}\text { Miller et a }\left.\right|^{32} \text { USA (four states) } \\
\text { Screening programme through unions, 1997-2004 } \\
\text { (medicolegal evaluation) } \\
n=4003\end{array}$ & One reader, blinded & $\begin{array}{l}\text { Smoking data by group not reported } \\
\text { and not included in analysis. }\end{array}$ & \\
\hline $\begin{array}{l}\text { Ohlson et } a^{33} \text { Sweden } \\
\text { Asbestos cement plant } \\
\text { Screening in } 1976 \text { (after plant closed), participation } \\
\text { rate } 96 \% \\
n=75 \text { (used follow-up data because quantitative } \\
\text { results reported) }\end{array}$ & $\begin{array}{l}\text { One reader, blinding not } \\
\text { reported }\end{array}$ & $\begin{array}{l}\text { Less than } 10 \text { pack-year difference } \\
\text { between groups }\end{array}$ & $\begin{array}{l}\text { Profusion scores details not discussed } \\
\text { Pleural plaques (not defined), } n=42 \\
\text { No pleural plaques, } n=51\end{array}$ \\
\hline $\begin{array}{l}\text { Oliver et } a l^{34} \text { Pennsylvania } \\
\text { Railroad workers } \\
\text { Screening study } \\
\mathrm{n}=377\end{array}$ & $\begin{array}{l}\text { Two readers, blinding not } \\
\text { reported }\end{array}$ & Adjusts for smoking in the analysis & $\begin{array}{l}\text { Excluded profusion scores } \geq 0 / 1 \\
\text { Plaque-like thickening, } n=81 \\
\text { No plaques, } n=278\end{array}$ \\
\hline $\begin{array}{l}\text { Schwartz et a }{ }^{35} \text { lowa } \\
\text { Sheet metal workers union, } 1223 \text { of } 2646(46 \%) \\
\text { participated } \\
n=1211 \text { with X-rays }\end{array}$ & $\begin{array}{l}\text { One reader (plus } 10 \% \\
\text { validation study), blinded }\end{array}$ & Adjusts for pack-years in analysis & $\begin{array}{l}\text { Excluded profusion scores } \geq 1 / 0 \text { (table } 9 \text { ) } \\
\text { Circumscribed plaque without obliteration of } \\
\text { costophrenic angle, } n=260 \text { (before profusion } \\
\text { score exclusion) } \\
\text { No pleural changes, } n=877 \text { (before } \\
\text { profusion score exclusion) }\end{array}$ \\
\hline $\begin{array}{l}\text { Singh et } a^{21} \text { Australia } \\
\text { Asbestos-exposed (various sources) } \\
\text { Seen in outpatient clinic because of asbestos } \\
\text { exposure, 1994-1995 } \\
\mathrm{n}=26\end{array}$ & $\begin{array}{l}\text { One reader, blinding not } \\
\text { reported }\end{array}$ & $\begin{array}{l}\text { Difference in smoking prevalence ( } 8 \% \\
\text { and } 0 \% \text {, based on single individuals) } \\
\text { not addressed }\end{array}$ & $\begin{array}{l}\text { Profusion scores details not discussed } \\
\text { Costal and/or diaphragmatic plaques with } \\
\text { no involvement of costophrenic angle, } n=12 \\
\text { No pleural disease, } n=7\end{array}$ \\
\hline $\begin{array}{l}\text { Weill et } a{ }^{36} \text { Montana (Libby) } \\
\text { Community screening, former workers, family } \\
\text { members and other area residents } \\
n=4397\end{array}$ & $\begin{array}{l}\text { Consensus of two of } \\
\text { three readers, blinding } \\
\text { not reported }\end{array}$ & $\begin{array}{l}\text { Stratified by smoking status (ever/ } \\
\text { never) within men and women }\end{array}$ & $\begin{array}{l}\text { Excluded profusion scores } \geq 1 / 0 \\
\text { Pleural abnormality excluding DPT, } \\
\text { costophrenic angle obliteration or interstitial } \\
\text { disease, } n=482 \\
\text { No abnormality, } n=4065\end{array}$ \\
\hline $\begin{array}{l}\text { Zavalić and Bogadi-Sare }{ }^{37} \text { Croatia } \\
\text { Shipyard workers }\end{array}$ & $\begin{array}{l}\text { Consensus of two of } \\
\text { three readers, blinding } \\
\text { not reported }\end{array}$ & $\begin{array}{l}\text { Authors noted smoking distribution } \\
\text { similar across groups }\end{array}$ & $\begin{array}{l}\text { Excluded profusion scores }>0 / 0 \text { from } \\
\text { analysis of table } 5 \\
\text { Pleural plaques only, } n=68 \\
\text { No changes, } n=101\end{array}$ \\
\hline
\end{tabular}


Table 2 Cross-sectional (internal comparison group) high-resolution CT (HRCT) studies of pleural plaques and lung function included in meta-analysis

\begin{tabular}{|c|c|c|c|}
\hline Reference, population & $\begin{array}{l}\text { X-ray or HRCT } \\
\text { details }\end{array}$ & Smoking consideration & Study groups \\
\hline $\begin{array}{l}\text { Clin et } a l^{38} \text { France } \\
\text { Exposed workers (retired or inactive) } \\
\text { Various recruitment strategies (letters, union, } \\
\text { advertisements) for medical surveillance } \\
\text { programme } \\
n=2743\end{array}$ & $\begin{array}{l}\text { Two readers (out of } \\
\text { group of } 7 \text { ), blinded }\end{array}$ & Adjusts for smoking in the analysis & $\begin{array}{l}\text { Isolated pleural plaques, } n=403 \\
\text { Normal, } n=1802\end{array}$ \\
\hline $\begin{array}{l}\text { Oldenberg et al }{ }^{39} \text { Germany } \\
\text { Registry of asbestos-exposed workers } \\
\text { ( } n \sim 500000 \text { ), approximately } 2 / 3 \text { undergo periodic } \\
\text { exams; this study conducted in Bocham area } \\
n=43\end{array}$ & $\begin{array}{l}\text { Reading protocol not } \\
\text { reported }\end{array}$ & Analyses stratified by smoking status & $\begin{array}{l}\text { Pleural plaques only, } n=21 \\
\text { Normal, } n=22\end{array}$ \\
\hline $\begin{array}{l}\text { Rui et } a l^{24} \text { Italy } \\
\text { Workers referred to occupational medicine clinic } \\
\text { 1991-2000; Included workers with pleural } \\
\text { plaques on X-ray who were further referred for } \\
\text { HRCT. } \\
n=103\end{array}$ & $\begin{array}{l}\text { One reader, blinding } \\
\text { not reported }\end{array}$ & $\begin{array}{l}\text { Less than } 10 \% \text { difference in smoking } \\
\text { prevalence between groups }\end{array}$ & $\begin{array}{l}\text { Pleural plaques only, } n=36 \\
\text { Normal, } n=67\end{array}$ \\
\hline $\begin{array}{l}\text { Soulat et }\left.a\right|^{40} \text { France } \\
\text { Nitrate fertiliser plant with asbestos insulation } \\
350 \text { former workers identified; } \\
254 \text { potentially exposed, still living; } \\
n=170 \text { participants }\end{array}$ & One reader, blinded & $\begin{array}{l}\text { Smoking data by group not reported } \\
\text { and not included in analysis }\end{array}$ & $\begin{array}{l}\text { Pleural thickening only, } n=84 \\
\text { No abnormalities, } n=51\end{array}$ \\
\hline $\begin{array}{l}\text { van Cleemput et al }{ }^{22} \text { Belgium } \\
\text { Asbestos cement factory (current workers) } \\
n=73 \text { (out of } 88 \text { identified workers; } 3 \text { of } 15 \\
\text { non-participants had plaques) }\end{array}$ & Three readers, blinded & $\begin{array}{l}\text { Smoking data by group not reported } \\
\text { and not included in analysis }\end{array}$ & $\begin{array}{l}\text { Used X-ray rather than HRCT to exclude individuals } \\
\text { with asbestosis (excluded profusion scores }>1 / 0 \text { ) } \\
\text { Pleural plaques, } n=51 \\
\text { No pleural plaques, } n=22\end{array}$ \\
\hline
\end{tabular}

The outcomes are \%pred values for FVC and $\mathrm{FEV}_{1}$, where predicted values are adjusted for age, sex and height. The potential confounding effects of smoking were addressed in various ways by 14 of the studies: stratification, ${ }^{23} 39$ adjustment, ${ }^{34} 3638$ exclusion of ever smokers ${ }^{30}$ and indication that there was no or only a small difference in the smoking distribution between groups. $^{24-26} 282933 \quad 3537$ Two studies ${ }^{36} 38$ additionally controlled for the effects of body mass index (BMI). One study ${ }^{33}$ presented results stratified by exposure level and three studies $^{26} 3438$ adjusted for a cumulative asbestos exposure index or duration of exposure. These factors (smoking, BMI and asbestos exposure) were not measured in all studies, but the use of an internal comparison group (ie, exposed workers) should minimise differences in these factors when comparing those with no radiographic or HRCT abnormalities and those with pleural plaques.

Among the studies identified for the meta-analyses, specific limitations pertaining to participant selection, data collection and analysis were noted as follows:

- Recruitment through clinic setting, or other attributes of recruitment, that may have led to overselection of symptomatic individuals; ${ }^{21} 242832$

- Only one X-ray or HRCT reader or different readers in different locations (without validation sample), or lack of details about X-ray or HRCT reading protocol; $21232430-333940$

- Lack of blinding (or lack of reporting of blinding) of X-ray or HRCT readers to asbestos exposure or medical history; ${ }^{21} 232429303334363739$

- Inadequate consideration of smoking as a potential confounder. 212227313240

These 16 studies were not excluded from further consideration, but additional sensitivity analyses were conducted to evaluate the potential effect of these identified limitations on the results of the meta-analyses.

\section{RESULTS}

\section{Meta-analysis of cross-sectional studies}

The cross-sectional studies were all conducted among occupationally exposed workers, from a variety of industries (eg, shipbuilding, railroad workers, etc). Study participants were generally male, with mean age at examination of $\sim 50-60$ years. Figure 1 (FVC) figure $2\left(\mathrm{FEV}_{1}\right)$ show individual study results as well as the summary effect estimates resulting from the meta-analyses. The summary effect estimates for FVC and FEV 1 are statistically significant, showing a change of $-4.09 \%$ pred (95\% CI -5.86 to -2.31 ) and $-1.99 \%$ pred $(95 \% \mathrm{CI}-3.77$ to $-0.22)$, respectively. The results of larger studies are very consistent in showing a decrease in FVC (see figure 1). In contrast, fewer large studies are available for $\mathrm{FEV}_{1}$, and there is less consistency in the results (see figure 2). The use of random effect models was supported for both pulmonary measures, as the tests for heterogeneity were statistically significant, and the $\mathrm{I}^{2}$ was $80 \%$ and $57 \%$ for FVC and $\mathrm{FEV}_{1}$, respectively (where $\mathrm{I}^{2}$ represents the proportion of the total variation across studies due to study heterogeneity instead of chance).

Analysis of the HRCT studies is separately shown in figure 3. Although, the number of study participants varied widely across HRCT studies, for both measures of lung function, results of HRCT studies considered separately are quite similar in magnitude to overall results (combining the two study types) and to X-ray results. For FVC, results from HRCT and X-ray studies considered as separate sets are statistically significant: $-3.30 \%$ pred $(95 \%$ CI -5.25 to -1.34$)$ and $-4.55 \%$ pred $(95 \%$ CI -6.73 to -2.38 ), respectively; $\mathrm{FEV}_{1}$ results for HRCT and $\mathrm{X}$-ray studies considered separately were very similar in magnitude to the combined results, but are not statistically significant: $-1.96 \%$ pred (95\% CI -6.01 to 2.09 ) and $-1.87 \%$ pred $(95 \%$ CI -3.96 to 0.23 ), respectively. Given that the overall (combined) results for $\mathrm{FEV}_{1}$ are statistically significant, this is likely 


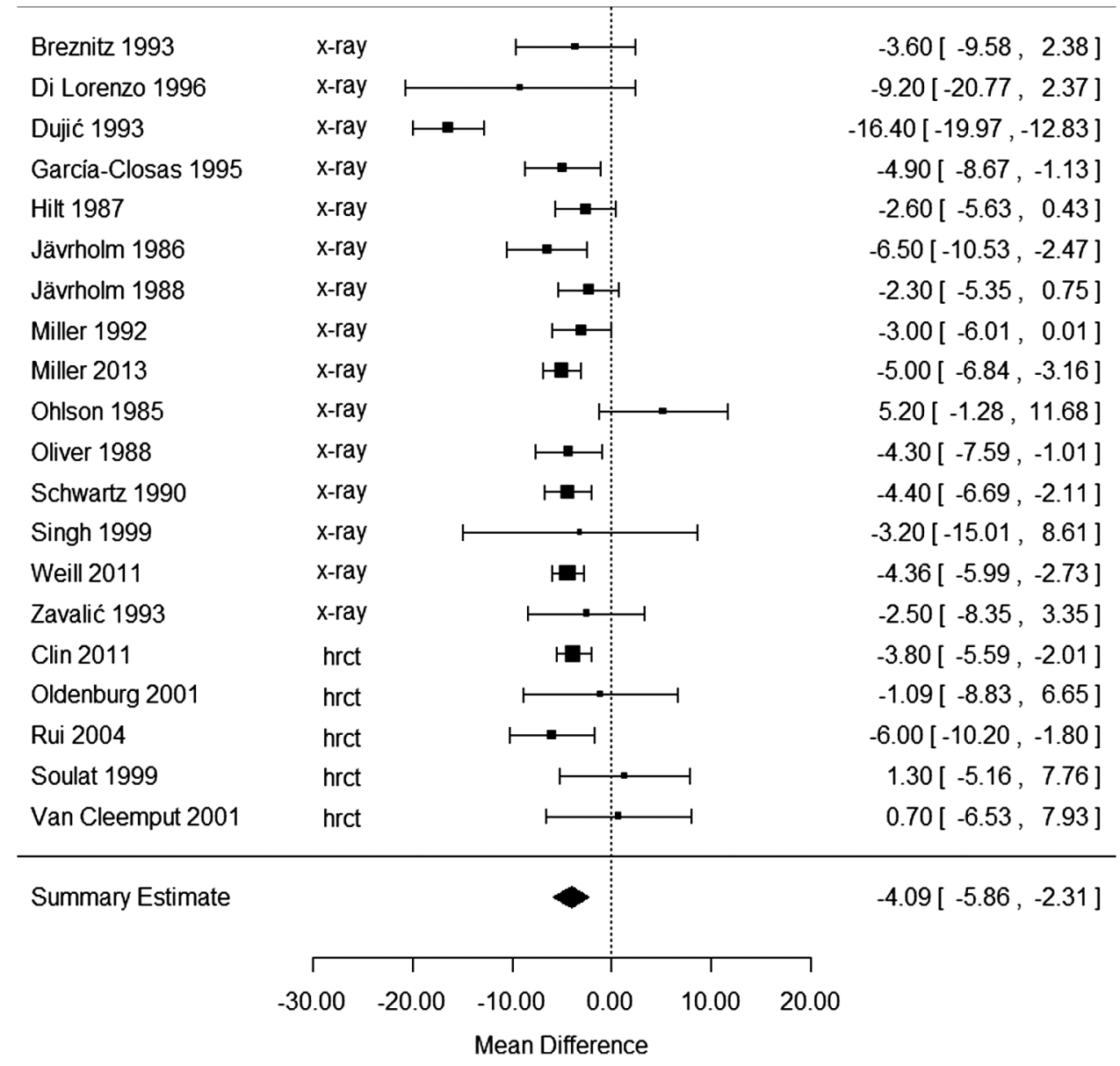

Figure 1 Study-specific and summary effect estimates for change in per cent predicted forced vital capacity comparing asbestos-exposed groups with and without pleural plaques, X-ray and high-resolution CT (HRCT) cross-sectional studies. Data are mean values; bars and values in brackets are $95 \% \mathrm{Cl}$, size of data point is proportional to study weight.

due to the smaller sample sizes when X-ray and HRCT studies are separated. There were no clear asymmetries in the examination of funnel plots (see online supplementary material) for all the analyses (although for HRCT analyses there were few data points) suggesting that publication bias is not an issue in these analyses.

For sensitivity analysis, we first excluded studies with the limitations described in the Methods section from the meta-analysis; 16 and 12 , respectively, were excluded in the FVC and $\mathrm{FEV}_{1}$ analyses. The results were more consistent (narrower CI despite a smaller number of studies) with a summary effect estimate of $-4.08 \%$ pred $(95 \%$ CI -5.44 to -2.71 ) for FVC (based on four studies ${ }^{25} 263538$ ) and an effect for $\mathrm{FEV}_{1}$ that is almost doubled compared with the full set analysis (-3.87\%pred, 95\% CI -5.84 to -1.90 ; based on three studies 2538 ). Next, one study at a time was excluded to evaluate influence of individual studies on the summary effect measures. No one study showed a notable influence on the summary results, which changed by $<8 \%$ for $\mathrm{FVC}$, and between $-18 \%$ and $+25 \%$ for $\mathrm{FEV}_{1}$. In addition, examination of the studies excluded because of analysis or reporting issues (see online supplementary table S2) indicates that the qualitative results of this additional set of studies are also consistent with the pattern seen in figures 1 and 2, with three of the five studies in online supplementary table S2 indicating a decrement in FVC in the pleural plaque group, compared with the no pleural plaque group (two studies did not state if there was a decrease or increase).

\section{Relationship between lung function measures and extent of pleural plaques}

Four cross-sectional studies also presented analyses of the extent of pleural plaques in relation to degree of decrement in lung function. $^{22} 373848$ Lilis et $a l^{48}$ is related to the Miller et al ${ }^{31}$ study included in the meta-analysis. In the study by Clin et al, ${ }^{38}$ the decrease in FVC seen with increasing maximum cumulative plaque extent was statistically significant, and for $\mathrm{FEV}_{1}$ the decrease was marginally significant $(p=0.06)$; there was a difference of approximately $-4 \%$ pred in \%pred FVC and \%pred $\mathrm{FEV}_{1}$ when comparing the lowest to the highest plaque extent category. In the study by Lilis et $a l,{ }^{48}$ a higher index score (indicating increased pleural plaque size) was significantly associated with a larger decrement of 5-10\%pred FVC (accounting for smoking and time since first exposure) compared with a lower index score. Van Cleemput et al ${ }^{22}$ reported a non-significant decrease in \%pred VC and \%pred $\mathrm{FEV}_{1}$ with increasing total surface area of pleural plaques; however, on average those with pleural plaques had slightly better lung function than those without pleural plaques. Although van Cleemput et $a l^{22}$ concluded that neither the presence nor the extent of the plaques was correlated with lung function parameters, this is a small study of only 73 workers compared with more than 2000 workers in the study by Clin et al, ${ }^{38}$ which found that \%pred FVC and \%pred $\mathrm{FEV}_{1}$ both tended to decrease with increased plaque length. Zavalic et $a l^{37}$ reported that \%pred FVC as well as \%pred $\mathrm{FEV}_{1}$ tended to become lower with increases in 


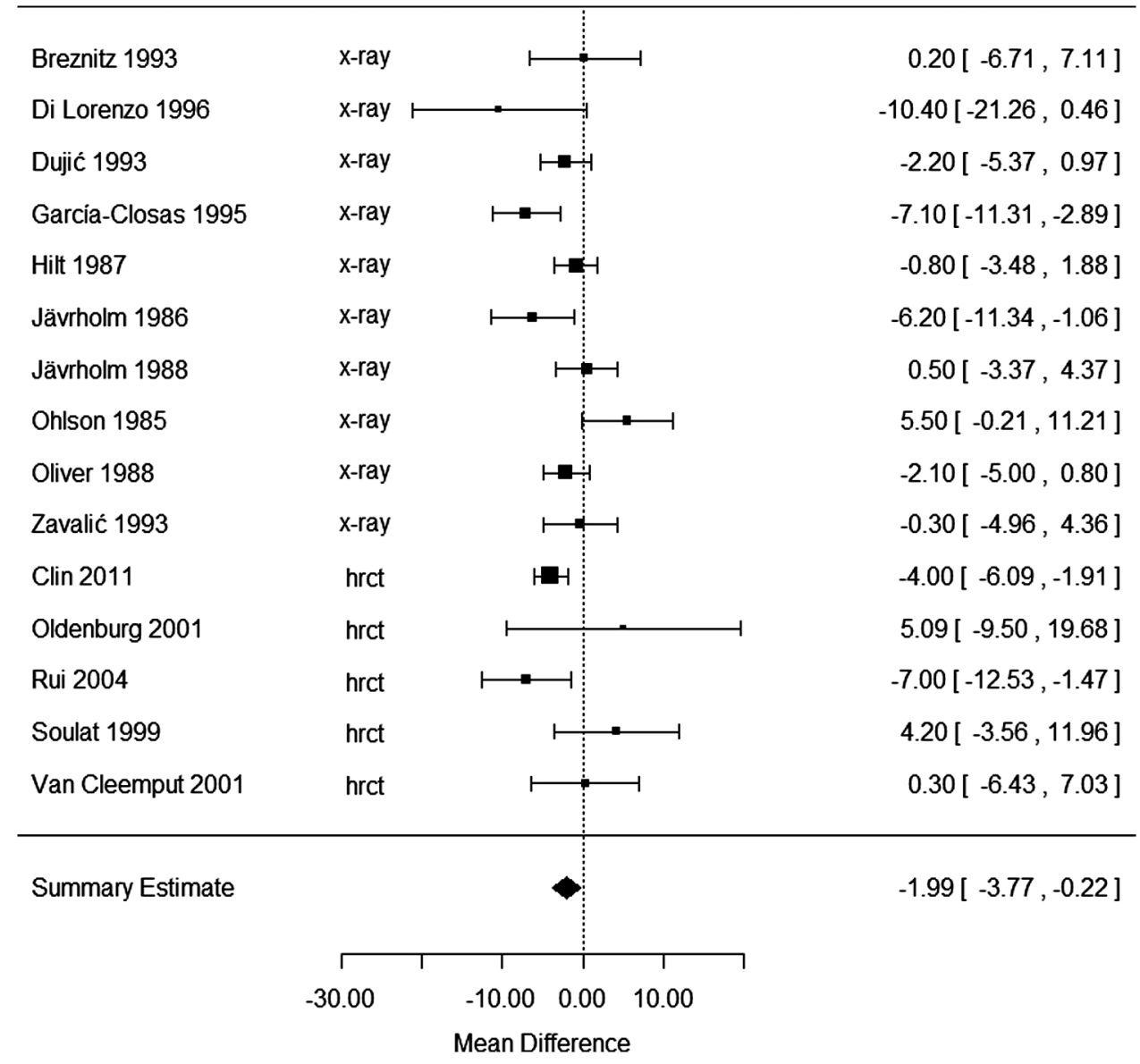

Figure 2 Study-specific and summary effect estimates for change in per cent predicted FEV1 comparing asbestos-exposed groups with and without pleural plaques, X-ray and high-resolution CT (HRCT) cross-sectional studies. Data are mean values; bars and values in brackets are $95 \% \mathrm{Cl}$, size of data point is proportional to study weight.

plaque length. Additionally, the longitudinal study by Sichletidis et $a l^{49}$ demonstrated that after 15 years of follow-up, the total surface area of pleural plaques increased twofold and lung function was statistically significantly decreased over that period. Although increased plaque surface area was not statistically significantly associated with the observed reductions in \%pred FVC or \%pred $\mathrm{FEV}_{1}$, the reduction in total lung capacity was associated with plaque surface area $(r=-0.486, p=0.041)$. Taken together, these studies strongly suggest that the extent of the decrease in lung function is associated with the extent (size or total surface area) of pleural plaques.

\section{Analysis by categorical, rather than continuous measures of lung function}

Three studies presented analyses in terms of difference in the proportion of individuals within a group below a specified value for the lung function test or combination of tests. In the study by Oliver et $a l{ }^{34}$ the proportion with FVC $<80 \%$ pred was approximately doubled in the pleural plaque group (18.5\%) compared with the group with no pleural plaques (9\%; relative risk: $2.1,95 \%$ CI 1.1 to 3.7 ); the smoking-adjusted mean difference between these two groups was $-4.3 \%$ pred FVC, similar to the summary effect estimate for all studies in our meta-analysis. García-Closas and Christiani ${ }^{28}$ observed a non-statistically significant increase in the proportion classified as having restrictive disease (defined as FVC $<80 \%$ predicted and $\mathrm{FEV}_{1} / \mathrm{FVC}$ $>75 \%$ ), from $3.9 \%$ in the group with no pleural plaques to
$7.8 \%$ in the pleural plaques group. In the study by Dujić $e t$ al, ${ }^{27}$ the estimated relative risk for restrictive disease (defined as FVC $<80 \%$ pred and $\mathrm{FEV}_{1} / \mathrm{FVC} \geq 70 \%$ ) in the group with pleural plaques, compared with the group with no pleural plaques, was 2.6 (95\% CI 1.7 to 3.9); the results in terms of mean difference in \%pred FVC between groups in this study were notably larger than other studies in figure 1 . The risk of obstructive disease in these studies were not different between those with plaques compared with those without pleural plaques, where obstructive disease was defined as $\mathrm{FEV}_{1}<80 \%$ pred and either $\mathrm{FEV}_{1} /$ $\mathrm{FVC}<70 \%{ }^{27}$ or $\mathrm{FEV}_{1} / \mathrm{FVC} \leq 75 \%{ }^{28}$ However, the increase in the proportion of individuals with mixed-pattern disease (FVC and $\mathrm{FEV}_{1}<80 \%$ pred, and $60 \%<\mathrm{FEV}_{1} / \mathrm{FVC}<75 \%$ ), from $1.3 \%$ in the no plaques group to $6.5 \%$ in the plaques group, was significant in the study by García-Closas and Christiani. ${ }^{28}$

\section{Evidence that the observed effect is not due to undetected parenchymal changes detectable by HRCT}

Analysis of HRCT studies alone showed that undetected parenchymal changes in X-ray examinations (but which would be detectable using HRCT) are not likely to explain the observed effects on lung function. The decrease in FVC observed in HRCT studies was somewhat smaller than that shown in X-ray studies (although still statistically significant); for $\mathrm{FEV}_{1}$ there was little difference in the effect size, although this estimated effect was not statistically significant in the smaller set of HRCT studies. 
FVC

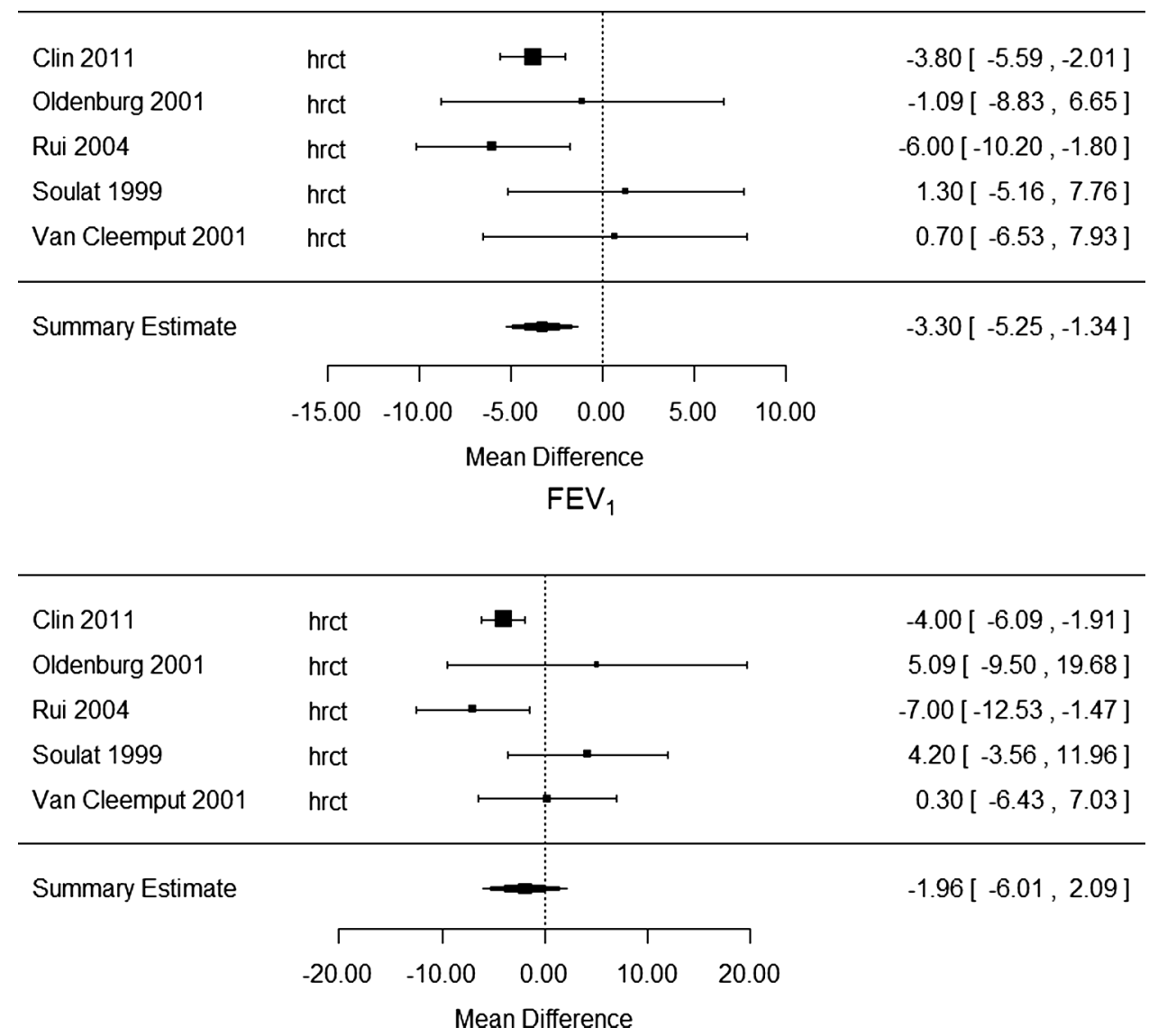

Figure 3 Study-specific and summary effect estimates for change in per cent predicted forced vital capacity (FVC; top panel) and forced expiratory volume in $1 \mathrm{~s}\left(\mathrm{FEV}_{1}\right.$; bottom panel) comparing asbestos-exposed groups with and without pleural plaques, for high-resolution CT (HRCT) cross-sectional studies. Data are mean values; bars and values in brackets are $95 \% \mathrm{Cl}$, size of data point is proportional to study weight.

\section{Analysis of longitudinal studies}

Longitudinal studies allow for evaluating the progression of pleural plaques over time, as seen by an increase in the extent of pleural plaques or thickening and a corresponding increase in lung function deficits with the passage of time. Only four longitudinal studies were found in the literature search. The mean length of follow-up varied among these studies from 3.7 to 15 years, with the longer follow-up periods providing evidence supporting an association between pleural plaques and increased rate or degree of pulmonary impairment (see online supplementary table S5). The presence of pleural plaques was not related to differences in decline in \%pred FVC or \%pred $\mathrm{FEV}_{1}$ measures in the studies with the shortest follow-up (3.7-4 years)..$^{24} 33$ In a case-control study with a 7-year follow-up, decreases in FVC of $31 \pm 12($ mean \pm SE) and $15 \pm 6 \mathrm{~mL} /$ year were seen in those with and without pleural plaques, respectively, but this difference between groups was not statistically significant. ${ }^{50}$ In the small study of people with plaques only, but with the longest follow-up period, the size of pleural plaques grew more than twofold (from 8.5 to $17.2 \mathrm{~cm}^{2}$ ) over approximately 15 years, ${ }^{49}$ and there was a large and statistically significant decrease of $14.6 \%$ pred FVC and 4.3\%pred FEV 1 over the follow-up period. The use of \%pred values by Sichletidis et al ${ }^{49}$ accounts for the expected decline with increasing age over the follow-up period. In addition, the observed pulmonary decrements are unlikely to be the result of continued asbestos exposure; Ostiguy et $a l^{50}$ stated that additional exposure during the follow-up period was low, while Sichletidis et al ${ }^{49}$ stated that there was no additional exposure during the follow-up period.

\section{DISCUSSION}

This systematic review demonstrates statistically significant decrements of 4.09\%pred FVC (95\% CI 2.31 to 5.86) and $1.99 \%$ pred $\mathrm{FEV}_{1}$ (95\% CI 0.22 to 3.77 ) in people exposed to asbestos with pleural plaques relative to exposed people with no pleural plaques. While the total decrement in either group could be due in part to asbestos exposure alone, the estimated difference between the groups should primarily reflect the decrement due to pleural plaques. In the meta-analysis by Wilken et $a l,{ }^{8}$ asbestos-exposed workers without radiological abnormalities showed decrements in lung function (ie, values below 100\% of predicted: \%pred FVC 95.7 and \%pred FEV 93.6). Thus, the lung function decrements associated with pleural plaques in this analysis are even more pronounced when compared with $100 \%$ pred, or normal lung function.

Cross-sectional studies also suggest that increased extent of pleural plaques is associated with greater decrements in lung function. Regarding evidence from longitudinal studies; while two of these had very short follow-up periods of less than 5 years, ${ }^{24} 33$ the study with a 15 -year follow-up ${ }^{49}$ showed significant decreases in lung function.

Analysis of HRCT studies alone showed similar results to those of the X-ray studies alone. Thus, undetected parenchymal abnormalities are unlikely to fully account for the lung function 
decrements observed in X-ray studies. It is also unlikely that the observed association between pleural plaques and lung function decrements reflects solely an independent effect of asbestos exposure on lung function. In this analysis, we compared exposed workers with plaques to exposed workers without plaques: this comparison should reduce the potential influence of differences in exposure on the analysis, although it does not eliminate the possibility that workers with pleural plaques had higher exposure. However, the largest HRCT study controlled for cumulative exposure, as well as other potential confounders, and demonstrated significant pulmonary function decrease consistent with our summary effect estimate. ${ }^{38}$ Similar results were obtained in a large X-ray study ${ }^{34}$ that controlled for duration of exposure. A smaller study that stratified for exposure observed a tendency for better lung function among workers with versus without pleural plaques. ${ }^{33}$ Overall, these results indicate that differences in asbestos exposure are unlikely to fully explain the observed differences in lung function. It is possible, however, that people more sensitive to the effect of asbestos exposure, given the same level of exposure, develop pleural plaques and also have a larger decrease in lung function. In that case, plaques may not be the cause of the decrease in lung function, but are a marker for susceptibility to pulmonary effects of asbestos.

Specific aspects of the design or analysis of these studies indicate that the demonstrated association of pleural plaques and lung function decrease are unlikely to be explained by other causes of lung function loss, such as demographic characteristics, smoking or other lung disease. The sensitivity analysis addressed limitations or potential biases noted through a systematic review of study methods conducted prior to evaluation of the results, including limitations in the way in which smoking was addressed and lack of an explicit statement that some kind of blinding procedure was used for the reading of the X-ray or HRCT. In this sensitivity analysis of studies without limitations in study methods, pulmonary decrements were essentially the same for FVC or increased almost twofold for $\mathrm{FEV}_{1}$ compared with the analysis including all of the studies and the decrements remained statistically significant. Medical reasons for decreases in pulmonary function were explicitly accounted for through exclusion of individuals with lung diseases in seven studies; $^{21} \quad 23 \quad 24 \quad 29 \quad 30 \quad 37 \quad 38$ since this type of exclusion is common, it may have been performed but not mentioned in some papers having limited details on participant recruitment and inclusion/exclusion criteria.

The 2000 ILO guidelines define the outcome of LPT as plaques with width of at least $3 \mathrm{~mm}$, a more sensitive and specific definition compared with the 1980 ILO guidelines. Although no studies reported results for plaques with width of at least $3 \mathrm{~mm}$ (ie, LPT), one large study ${ }^{38}$ reported results for plaques less than $2 \mathrm{~mm}$ and found that those with such plaques had at least 100\%pred FVC and $\mathrm{FEV}_{1}$. Thus, results of this analysis for pleural plaques can be seen to apply to LPT.

We have considered the potential for BMI to affect our observed associations between pleural plaques and lung function. Directionally consistent with this potential bias, we find a tendency for greater FVC decrements in the X-ray studies (4.55\%) relative to the HRCT studies (3.30\%). However, given that the FVC loss is still observed in the HRCT studies, the associations cannot be fully explained by effects of BMI. Of the two studies that included BMI in their analyses, one study, using $\mathrm{X}$-rays, observed a slightly higher BMI in people with plaques (mean 30.3 and $28.5 \mathrm{~kg} / \mathrm{m}^{2}$, respectively for with and without plaques), and higher BMI and age were significantly related to decrements in FVC; ${ }^{36}$ the results used in our meta-analysis are the BMI-adjusted and age-adjusted results. The other study used HRCT, and observed similar mean BMI between individuals with and without pleural plaques $\left(27.7\right.$ and $27.4 \mathrm{~kg} / \mathrm{m}^{2}$, respectively). ${ }^{38}$ More generally, the prediction of $\mathrm{FEV}_{1}$ and FVC is not improved by considering weight after taking into account height, age, race and sex in cross-section analyses of lung function. ${ }^{51}$ We do not believe large differences in BMI by radiographic group are likely in the remaining studies examined, and overall, we do not believe that our observed associations between pleural plaques and lung function decrements are biased by an effect of BMI.

With regard to fibre type, 13 studies did not report fibre type of asbestos exposure, 4 reported mixed exposure, 2 reported mostly chrysotile exposure and 1 reported Libby tremolite (Libby amphibole asbestos) exposure. Although we could not examine fibre characteristics in this analysis, we are not aware of any studies of pleural plaques and lung function that indicated potential differences in association by fibre. Moreover, the results from the studies included in this meta-analysis did not display great variability, although it is likely that study populations were exposed to different fibre types (or mixtures).

Although the changes in lung function found in our meta-analyses are relatively small (-4.09\%pred FVC; $-1.99 \%$ pred $\mathrm{FEV}_{1}$ ), these decrements are not inconsequential. The observed decrease in lung function should be considered on an individual as well as a population level. At the individual level, the decrement in FVC or $\mathrm{FEV}_{1}$ may or may not be noticeable for a given patient; while many with pleural plaques could have well-preserved lung function, there are some at the lower end of 'normal' lung function, for whom even a small additional decrement would result in an increased disease severity (eg, mild to moderate disease). Thus, at the population level, even small changes in the average of a distribution of lung function can result in a proportion of the exposed population shifted down into the lower 'tail' of the lung function distribution. This perspective was noted by the ATS in a 2000 article, ${ }^{52}$ which stated, "It should be emphasised that a small but significant reduction in a population mean $\mathrm{FEV}_{1}$ or $\mathrm{FEV}_{0.75}$, is probably medically significant, as such a difference may indicate an increase in the number of persons with respiratory impairment in the population. In other words, a small part of the population may manifest a marked change that is medically significant to them, but when diluted with the rest of the population the change appears to be small." In addition to the mean decrease in the lung function of exposed individuals with pleural plaques, longitudinal studies show a greater rate of decline in the lung function of asbestos exposed individuals with pleural plaques. Both, the mean decrease in lung function we observed and the greater rate of decline in lung function, are consequential from a public health perspective. ${ }^{52}$

Our review and meta-analyses indicate that pleural plaques (and consequently, LPT as defined in recent ILO guidelines) are associated with declines in lung function. This association is not likely to be fully explained by undetected parenchymal abnormalities. Although the average decrement lung function associated with the presence of pleural plaques may not be generally considered clinically significant, the relation between plaque size and degree of decrement, and the increase in size and decrement over time indicate these changes may be consequential to the exposed population.

Acknowledgements The authors thank Larissa Pardo for assistance. Competing interests None. 
Provenance and peer review Not commissioned; externally peer reviewed.

Open Access This is an Open Access article distributed in accordance with the Creative Commons Attribution Non Commercial (CC BY-NC 4.0) license, which permits others to distribute, remix, adapt, build upon this work non-commercially, and license their derivative works on different terms, provided the original work is properly cited and the use is non-commercial. See: http://creativecommons.org/ licenses/by-nc/4.0/

\section{REFERENCES}

1 WHO. Asbestos (chrysotile, amosite, crocidolite, tremolite, actinolite, and anthophyllite). Monographs on the evaluation of carcinogenic risks to humans. World Health Organization (WHO), International Agency for Research on Cancer (IARC), 2012.

2 USGS. 2012 Minerals Yearbook: ASBESTOS U.S. Department of the Interior. U.S. Geological Survey, 2013.

3 Van Gosen BS. The geology of asbestos in the United States and its practical applications. Environ Entomol 2007; XIII:55-68.

4 American Thoracic Society. Diagnosis and initial management of nonmalignant diseases related to asbestos. Am J Respir Crit Care Med 2004;170:691-715.

5 Lilis R, Miller A, Godbold J, et al. Radiographic abnormalities in asbestos insulators: effects of duration from onset of exposure and smoking. Relationships of dyspnea with parenchymal and pleural fibrosis. Am J Ind Med 1991;20:1-15.

6 Järvholm B. Pleural plaques and exposure to asbestos: a mathematical model. Int J Epidemiol 1992;21:1180-4.

7 Banks DE, Shi R, McLarty J, et al. American College of Chest Physicians consensus statement on the respiratory health effects of asbestos. Results of a Delphi study. Chest 2009;135:1619-27.

8 Wilken D, Velasco Garrido M, Manuwald U, et al. Lung function in asbestos-exposed workers, a systematic review and meta-analysis. J Occup Med Toxicol 2011;6:21.

9 ILO. Guidelines for the use of the ILO international classification of radiographs of pneumoconioses. Geneva, Switzerland: International Labour Office, 1980.

10 ILO. International classification of radiographs of pneumoconioses. Occupational Safety and Health Series. Geneva, Switzerland: International Labour Office, 2002.

11 Hjortsberg U, Ørbaek P, Aborelius M Jr, et al. Railroad workers with pleural plaques: I. Spirometric and nitrogen washout investigation on smoking and nonsmoking asbestos-exposed workers. Am J Ind Med 1988;14:635-41.

12 Kilburn $\mathrm{KH}$, Warshaw RH. Difficulties of attribution of effect in workers exposed to fiberglass and asbestos. Am J Ind Med 1991;20:745-51.

13 Schneider J, Arhelger R, Raab W, et al. The validity of static lung compliance in asbestos-induced diseases. Lung 2012;190:441-9.

14 Ameille J, Matrat M, Paris C, et al. Asbestos-related pleural diseases: dimensional criteria are not appropriate to differentiate diffuse pleural thickening from pleural plaques. Am J Ind Med 2004;45:289-96.

15 Fridriksson HV, Hedenström H, Hillerdal G, et al. Increased lung stiffness of persons with pleural plaques. Eur J Respir Dis 1981;62:412-24.

16 Hillerdal G. Pleural and parenchymal fibrosis mainly affecting the upper lung lobes in persons exposed to asbestos. Respir Med 1990;84:129-34.

17 Kilburn KH, Warshaw RH. Abnormal pulmonary function associated with diaphragmatic pleural plaques due to exposure to asbestos. Br J Ind Med 1990;47:611-14.

18 McLoud TC, Woods BO, Carrington CB, et al. Diffuse pleural thickening in an asbestos-exposed population: prevalence and causes. AJR Am J Roentgenol 1985; 144:9-18.

19 Chow S, Campbell C, Sandrini A, et al. Exhaled breath condensate biomarkers in asbestos-related lung disorders. Respir Med 2009;103:1091-7.

20 Sandrini A, Johnson AR, Thomas PS, et al. Fractional exhaled nitric oxide concentration is increased in asbestosis and pleural plaques. Respirology 2006;11:325-9.

21 Singh B, Eastwood PR, Finucane KE, et al. Effect of asbestos-related pleural fibrosis on excursion of the lower chest wall and diaphragm. Am J Respir Crit Care Med 1999;160(5 Pt 1):1507-15.

22 van Cleemput J, de Raeve H, Verschakelen JA, et al. Surface of localized pleural plaques quantitated by computed tomography scanning: no relation with cumulative asbestos exposure and no effect on lung function. Am J Respir Crit Care Med 2001;163(3 Pt 1):705-10.

23 Järvholm B, Larsson S. Do pleural plaques produce symptoms? A brief report. J Occup Med 1988;30:345-7.

24 Rui F, De Zotti R, Negro C, et al. [A follow-up study of lung function among ex-asbestos workers with and without pleural plaques]. Med Lav 2004;95:171-9.

25 Bresnitz EA, Gilman MJ, Gracely EJ, et al. Asbestos-related radiographic abnormalities in elevator construction workers. Am Rev Respir Dis 1993;147(6 Pt 1):1341-4.
26 Di Lorenzo L, Mele M, Pegorari MM, et al. Lung cinescintigraphy in the dynamic assessment of ventilation and mucociliary clearance of asbestos cement workers. Occup Environ Med 1996;53:628-35.

27 Dujić Z, Eterović D, Tocilj J. Association between asbestos-related pleural plaques and resting hyperventilation. Scand J Work Environ Health 1993;19:346-51.

28 García-Closas M, Christiani DC. Asbestos-related diseases in construction carpenters. Am J Ind Med 1995;27:115-25.

29 Hilt B, Lien JT, Lund-Larsen PG. Lung function and respiratory symptoms in subjects with asbestos-related disorders: a cross-sectional study. Am J Ind Med 1987;11:517-28.

30 Järvholm B, Sandén A. Pleural plaques and respiratory function. Am J Ind Med 1986:10:419-26.

31 Miller A, Lilis R, Godbold J, et al. Relationship of pulmonary function to radiographic interstitial fibrosis in 2,611 long-term asbestos insulators: an assessment of the International Labour Office profusion score. Am Rev Respir Dis 1992;145(2 Pt. 1):263-70.

32 Miller A, Widman SA, Miller JA, et al. Comparison of x-ray films and low-dose computed tomographic scans: demonstration of asbestos-related changes in 2760 nuclear weapons workers screened for lung cancer. J Occup Environ Med 2013;55:741-5

33 Ohlson CG, Bodin L, Rydman T, et al. Ventilatory decrements in former asbestos cement workers: a four year follow up. Br J Ind Med 1985;42:612-16.

34 Oliver LC, Eisen EA, Greene R, et al. Asbestos-related pleural plaques and lung function. Am J Ind Med 1988;14:649-56.

35 Schwartz DA, Fuortes LJ, Galvin JR, et al. Asbestos-induced pleural fibrosis and impaired lung function. Am Rev Respir Dis 1990;141:321-6.

36 Weill D, Dhillon G, Freyder L, et al. Lung function, radiologic changes and exposure: analysis of ATSDR data from Libby, Montana. Eur Respir J 2011;38:376-83.

37 Zavalić M, Bogadi-Sare A. Lung functions and chest radiographs in shipyard workers exposed to asbestos. Arh Hig Rada Toksikol 1993;44:1-8.

38 Clin B, Paris C, Ameille J, et al. Do asbestos-related pleural plaques on HRCT scans cause restrictive impairment in the absence of pulmonary fibrosis. Thorax 2011;66:985-91.

39 Oldenburg M, Degens $P$, Baur X. Asbest-bedingte Lungenfunktionseinschränkungen mit und ohne Pleuraplaques. Atemwegs-und Lungenkrankheiten 2001;27:422-3.

40 Soulat JM, Lauque D, Esquirol Y, et al. High-resolution computed tomography abnormalities in ex-insulators annually exposed to asbestos dust. Am J Ind Med 1999;36:593-601.

41 Bourbeau J, Ernst P, Chrome J, et al. The relationship between respiratory impairment and asbestos-related pleural abnormality in an active work force. Am Rev Respir Dis 1990;142:837-42.

42 Rosenstock L, Barnhart S, Heyer NJ, et al. The relation among pulmonary function, chest roentgenographic abnormalities, and smoking status in an asbestos-exposed cohort. Am Rev Respir Dis 1988;138:272-7.

43 Lebedova J, Dlouha $B$, Rychla $L$, et al. Lung function impairment in relation to asbestos-induced pleural lesions with reference to the extent of the lesions and the initial parenchymal fibrosis. Scand J Work Environ Health 2003;29:388-95.

44 Neri S, Boraschi P, Antonelli A, et al. Pulmonary function, smoking habits, and high resolution computed tomography (HRCT) early abnormalities of lung and pleural fibrosis in shipyard workers exposed to asbestos. Am J Ind Med 1996;30:588-95.

45 Staples CA, Gamsu G, Ray CS, et al. High resolution computed tomography and lung function in asbestos-exposed workers with normal chest radiographs. Am Rev Respir Dis 1989;139:1502-8.

46 Viechtbauer W. Conducting meta-analyses in $\mathrm{R}$ with the metafor package. J Stat Software 2010;36:1-48

47 Larson TC, Franzblau A, Lewin M, et al. Impact of body mass index on the detection of radiographic localized pleural thickening. Acad Radiol 2014;21:3-10.

48 Lilis R, Miller A, Godbold J, et al. Pulmonary function and pleural fibrosis: quantitative relationships with an integrative index of pleural abnormalities. Am J Ind Med 1991;20:145-61.

49 Sichletidis L, Chloros D, Chatzidimitriou N, et al. Diachronic study of pleural plaques in rural population with environmental exposure to asbestos. Am J Ind Med 2006:49:634-41.

50 Ostiguy G, Vaillancourt C, Bégin R. Respiratory health of workers exposed to metal dusts and foundry fumes in a copper refinery. Occup Environ Med 1995;52:204-10.

51 Hankinson JL, Odencrantz JR, Fedan KB. Spirometric reference values from a sample of the general US population. Am J Respir Crit Care Med 1999;159:179-87.

52 American Thoracic Society. What constitutes an adverse health effect of air pollution? Official statement of the American Thoracic Society. Am J Respir Crit Care Med 2000;161(2 Pt 1):665-73. 